\title{
Seismic velocity decrease and recovery related to earthquake swarms in a geothermal area
}

\author{
Takuto Maeda $^{1 * \dagger}$, Kazushige Obara ${ }^{1 \dagger}$, and Yohei Yukutake ${ }^{2}$ \\ ${ }^{1}$ National Research Institute for Earth Science and Disaster Prevention, Tennodai 3-1, Tsukuba, Ibaraki 305-0006, Japan \\ ${ }^{2}$ Hot Spring Research Institute, 586 Iriuda, Odawara, Kanagawa 250-0031, Japan
}

(Received April 5, 2010; Revised August 15, 2010; Accepted August 18, 2010; Online published December 13, 2010)

\begin{abstract}
We found a recurring seismic velocity decrease associated with small earthquake swarms experienced in 2007 in a geothermal area in Kyushu, southwestern Japan, by analyzing long-term changes in the autocorrelation function (ACF) of seismic noise. The seismic velocity decrease appeared just after two major periods of earthquake activity began in June and October of 2007. In both instances, conditions returned to normal within a characteristic time period of 4 months. The observed size of the velocity changes agrees well with the magnitudes of the swarms. The lag-time dependence of ACF changes can be systematically explained by seismic velocity changes induced by uid inclusion in a small, localized area deep within the hypocenter region.
\end{abstract}

Key words: Earthquake swarm, temporal change, seismic interferometry.

\section{Introduction}

The earth changes dynamically over time. Even in extremely short time frames of less than 1 year, changes happen in its crustal structure caused by dynamic phenomena such as earthquakes and volcanic eruptions. A temporal change in seismic velocity can be detected by observing very slight differences in seismograms traveling through an affected area. In particular, a comparison of coda waves from the tail portion of the seismogram is useful since these are sensitive to small changes in seismic velocity (e.g., Snieder et al., 2002). Cross-correlation between seismograms of repeating earthquakes (Poupinet et al., 1984; Yamawaki et al., 2004) and those of man-made arti cial earthquakes (Nishimura et al., 2005) has been a major method used to detect seismic velocity changes.

Seismic interferometry, a recently developed technique in seismology, enables researchers to extract Green's functions of seismic waves between two points using correlation functions of ambient noise or coda waves (e.g., Campillo and Paul, 2003; Shapiro et al., 2005). Passive image interferometry (PII) uses this concept in detecting changes through the monitoring of auto- and/or cross-correlation of daily ambient noise (Sens-Schönfelder and Wegler, 2006; Wegler and Sens-Schönfelder, 2007), with successful applications to coseismic changes (Ohmi et al., 2008; Brenguier et al., 2008a; Wegler et al., 2009) and changes associated

*Now at Center for Integrated Disaster Information Research, Interfaculty Initiative in Information Studies, the University of Tokyo, Japan.

${ }^{\dagger}$ Now at Earthquake Research Institute, the University of Tokyo, Japan.

Copyright (c) The Society of Geomagnetism and Earth, Planetary and Space Sciences (SGEPSS); The Seismological Society of Japan; The Volcanological Society of Japan; The Geodetic Society of Japan; The Japanese Society for Planetary Sciences; TERRAPUB.

doi:10.5047/eps.2010.08.006 with volcanic eruptions (Brenguier et al., 2008b). There are two physical mechanisms that may explain postseismic changes in velocity; one is a relaxation of fault zone damage by healing (Vidale and Li, 2003); the other is a nonlinear change in very shallow subsurface regions caused by the incidence of strong motion (Sawazaki et al., 2006). For velocity changes associated with large earthquakes, it is quite difcult to distinguish which mechanism is responsible. Here, using the PII technique, we found a temporal change in the seismic velocity that recurred in association with swarms of small earthquake activity.

\section{Earthquake Swarm Activity in NE Kyushu, Japan}

The earthquake swarms occurred in 2007 in a geothermal area with many hot springs and geysers (Kamata, 1989) located in the northeastern part of Kyushu in southwest Japan. Figure 1 shows the hypocentral distribution and temporal variation of the earthquake swarm determined by the National Research Institute for Earth Science and Disaster Preventions high-sensitivity seismograph network (NIED Hi-net) (Okada et al., 2004). The swarm activity is divided into two main stages. The rst active period began on June 5, 2007 at a depth of around $10 \mathrm{~km}$ and continued for 3 weeks. The hypocenters migrated southwestward and toward the surface. The second swarm activity, which lasted for 2 days from October 30, 2007, was shallower than that of the rst. Maximum local magnitudes of the rst and second periods were 5.0 and 3.3, respectively. The dominant focal mechanisms were of the normal-fault type containing strike-slip components (National Research Institute for Earth Science and Disaster Prevention, 2008; Fig. 1(b)), as re ected by the north/south-oriented extensional stress eld (Kamata, 1989) in this area. We did not observe any geodetic change associated with the active periods on the Hi-net tiltmeter records. 
(a)

$131.0^{\circ} \mathrm{E} \quad 131.2^{\circ} \mathrm{E} \quad 131.4^{\circ} \mathrm{E} \quad 131.6^{\circ} \mathrm{E} \quad 131.8^{\circ} \mathrm{E} \quad 132.0^{\circ} \mathrm{E}$

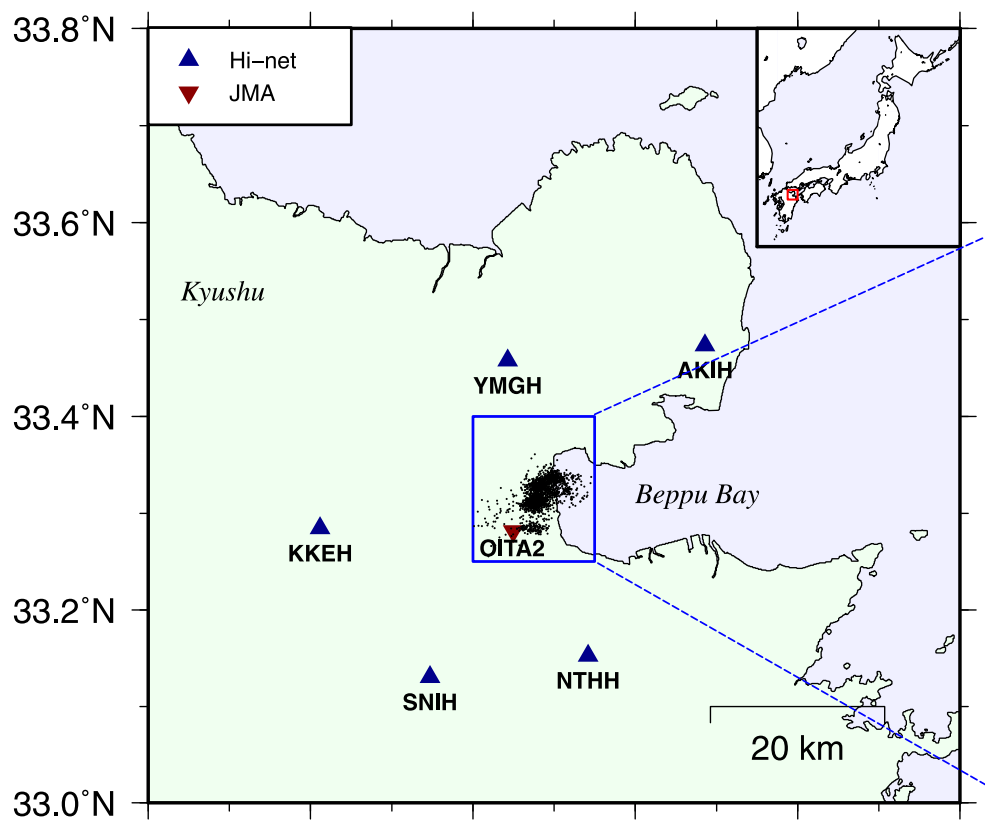

(b)

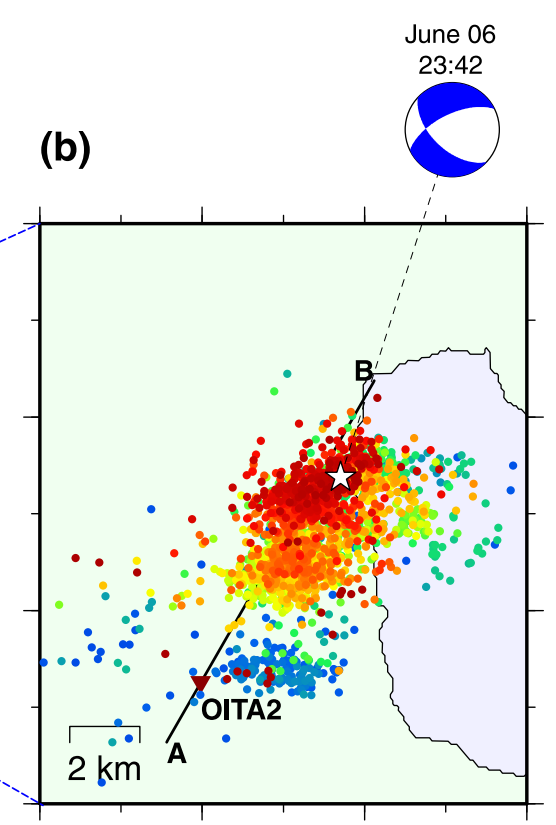

(c)

(d)
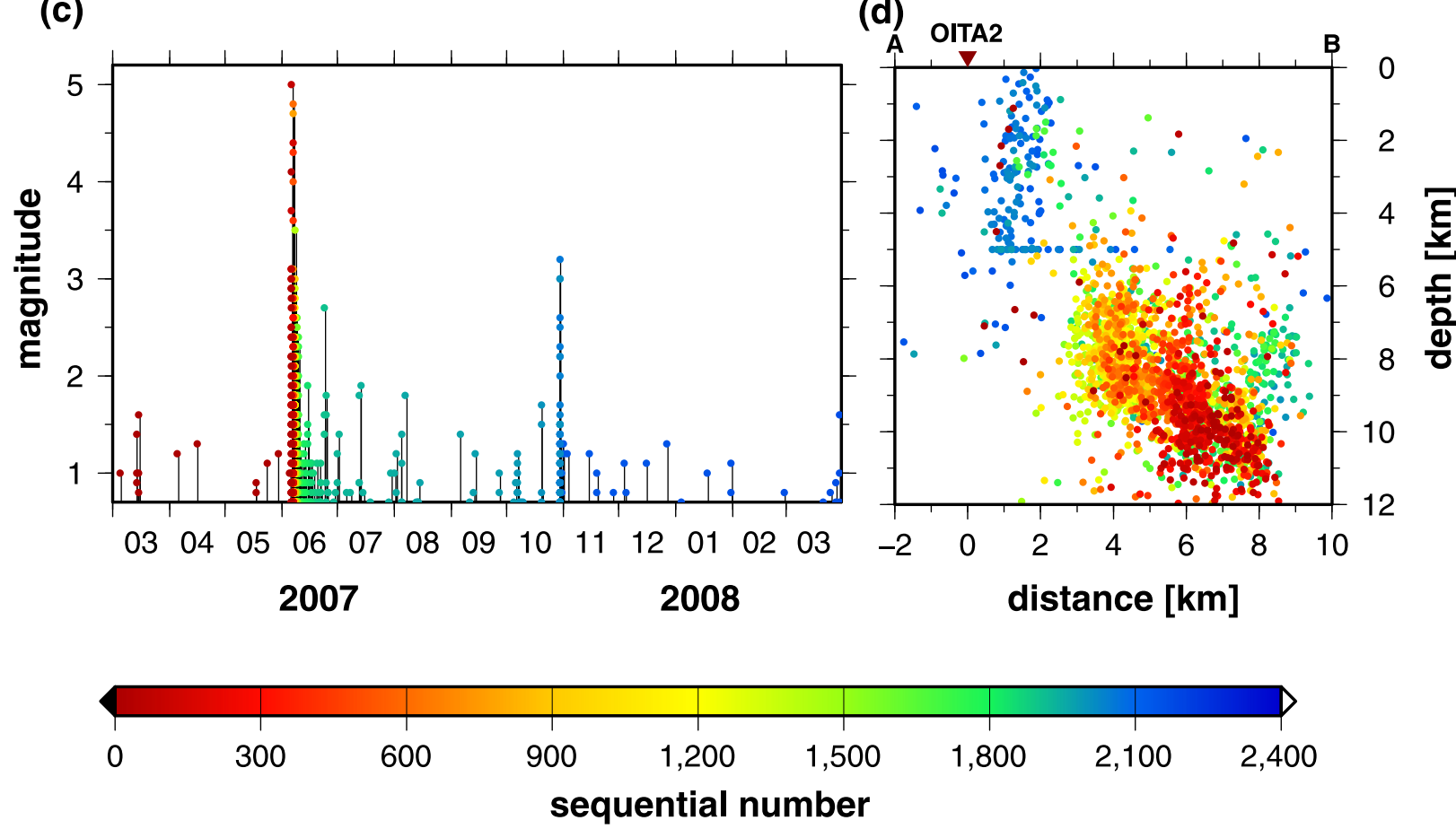

Fig. 1. (a) Study area index map. The red inverted triangle marks the location of a seismic station operated by the JMA (OITA2), while blue triangles show stations operated by NIED/Hi-net. A relocated epicenter distribution of earthquakes in the rectangular area is shown in (b). Symbol colors indicate the sequence of the earthquakes in this region, counting from June 1, 2007. The fault mechanism of the largest earthquake during the episode is shown above. (c) The bottom left panel shows a time-magnitude plot of the earthquake activity in the rectangular area. (d) Hypocenter depths along the A-B profile are shown in the bottom right panel.

\section{Temporal Changes in Noise Autocorrelation}

We investigated temporal changes in the autocorrelation function $(\mathrm{ACF})$ of ambient noise at the nearest station (OITA2) operated by the Japan Meteorological Agency (JMA), from the epicenter region of the seismic swarm. An ACF for every 1-h period was calculated from a continuous record of the short-period velocity seismometer with a sampling frequency of $100 \mathrm{~Hz}$ and natural frequency of $1 \mathrm{~Hz}$. The data was first filtered for the $1-3-\mathrm{Hz}$ bandwidth, then one-bit normalization (Shapiro et al., 2005) was applied to minimize the effect of non-noise records, such as earthquakes. Averaging ACFs for $24 \mathrm{~h}$ gives a 1-day ACF, which is used to monitor temporal changes.

Figure 2 shows daily ACFs of the vertical component of 
(a)

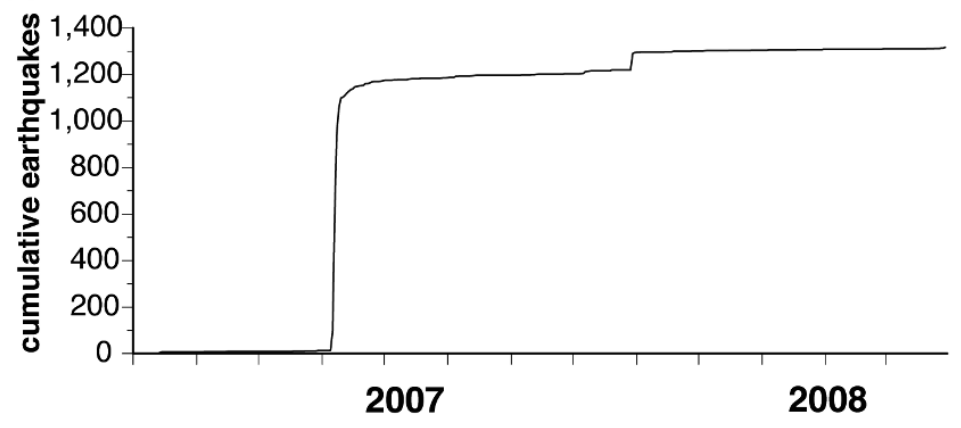

(b) $\quad \begin{array}{llllllllllllll}03 & 04 & 05 & 06 & 07 & 08 & 09 & 10 & 11 & 12 & 01 & 02 & 03\end{array}$

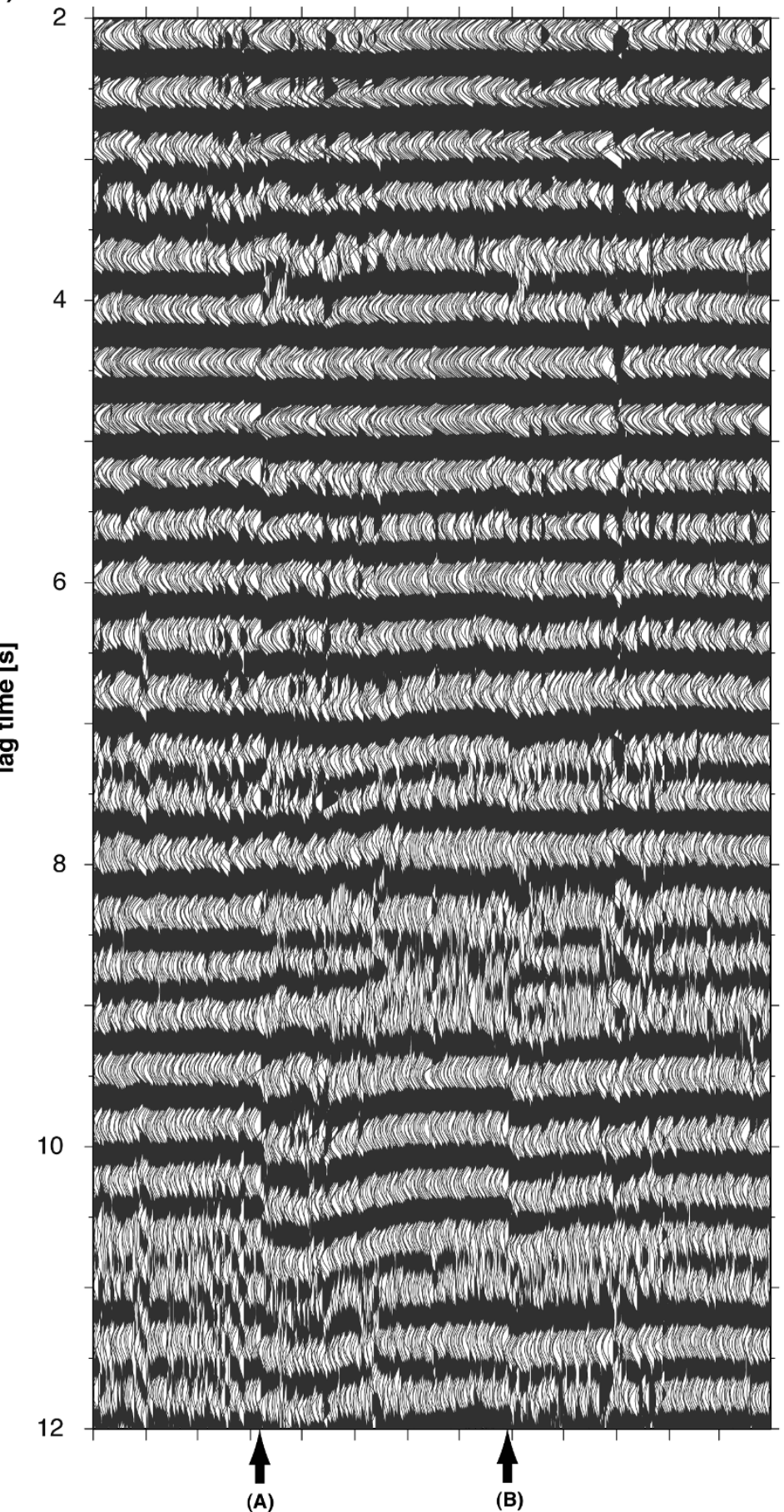

Fig. 2. Temporal changes in vertical component ACFs at OITA2 station for the frequency range of $1-3 \mathrm{~Hz}$. The number of earthquakes experienced in this region over time (Fig. 1) is shown above for the same period. Phases with positive signs are blue. Arrows mark the onset dates of periods of earthquake activity in mid-June and at the end of October. 
(a)

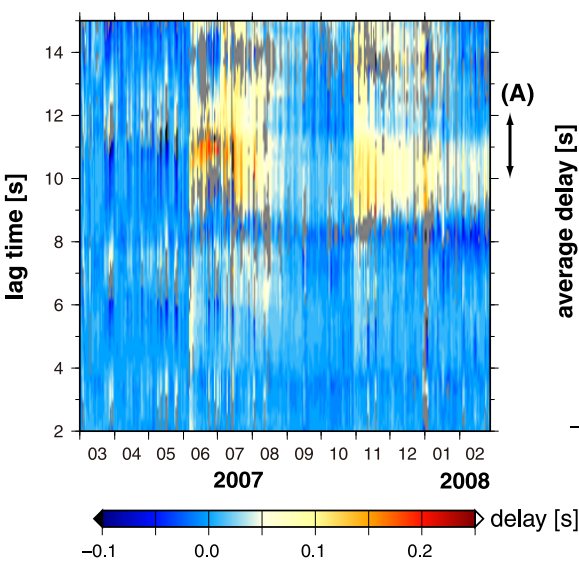

(b)

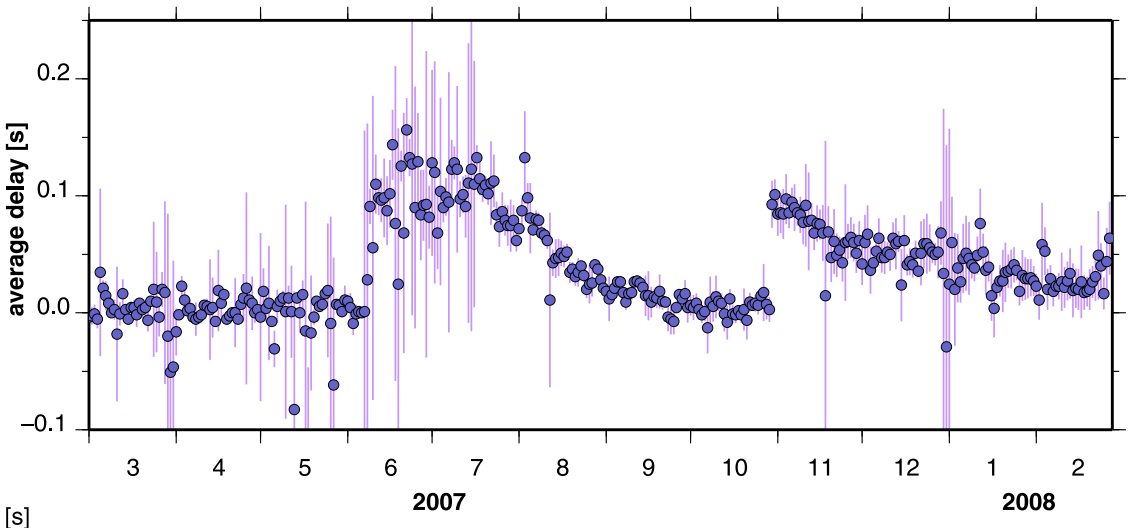

Fig. 3. (a) Lag time and time dependence of the relative ACF phase delay. The delay is measured through cross-correlation between 1-day ACFs and the ensemble average ACF for the period of January to March 2007 with a time window of $2 \mathrm{~s}$. If the maximum cross-correlation coefficient, which gives the phase delay, is less than 0.6, the delay estimate is excluded and shaded gray. (b) Average phase delay for lag times of 10-12 s (denoted by (A) in Fig. 3(a)). A circle bracketed by a one-standard deviation bar denotes the average delay for each date.

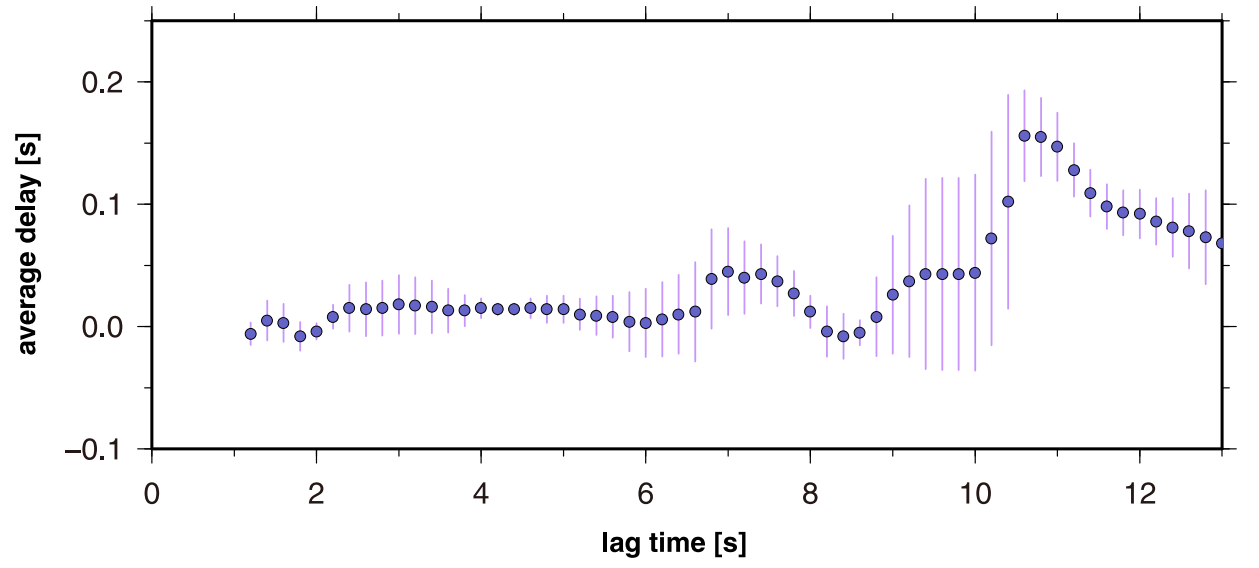

Fig. 4. Average ACF phase delay as a function of lag time for July 2007 obtained from cross-correlation analysis between 1-day ACFs and the ensemble average of ACFs for January to March 2007. The vertical bars extend to one standard deviation from the average.

seismic noise traces from January 2007 to March 2008 for a lag-time window of 2-12 s, together with a cumulative number of earthquakes of which magnitude is larger than 0.7 in the rectangular area in Fig. 1(a). Estimated ACFs are generally stable and coherent; they have very little seasonal change. However, at large lag times, there are rapid phase changes in mid-June and at the end of October (shown by arrows A and B in Fig. 2(b)). Both phase changes gradually recover over time. Onset of the sudden change agrees well with the beginning of the active earthquake periods. We note that the ACF phase delay clearly appears at lag times of around $10 \mathrm{~s}$. Since the PII technique assumes that the continuous seismic record mainly consists of noise coming from various directions, the estimation of noise ACF might be disturbed by the signal from swarm earthquakes; however, the change in ACF lasted longer than the periods of activity (Figs. 1(c), 2(b)). We applied the same signal processing at surrounding Hi-net stations (Fig. 1(a)). However, we observed no systematic changes, even though they clearly recorded seismic waves from the earthquake swarm. The temporal change is also found in ACFs of horizontal components at OITA2 station, however, the change is most significant in vertical component ACF.

To investigate the lag-time dependence of the ACF phase delay more quantitatively, the phase delay for every 2-s window during each day was measured by cross-correlating the 1-day ACF with the ensemble average of ACFs from January to March 2007 (Fig. 3). The dominant delay for both the June and October 2007 periods falls at lag times of 9-12 s. There are also small peaks of delay at lag times of 6-7 s and no delay at $8 \mathrm{~s}$. The temporal change of average phase delay for the lag time window of 10-12 s (denoted by (A) in Fig. 3(a)) indicates that the delays recovered to their pre-disturbance state within a characteristic period of 4 months (Fig. 3(b)). Figure 4 shows the average phase delay in horizontal space for July 2007, in which the phase delay is dominant. Two major phase delays are observed at lag times of 7-8 s and after $10 \mathrm{~s}$. Between them, no time delay is observed. It is noteworthy that there is no phase delay at lag times of less than $6 \mathrm{~s}$. 
(a)

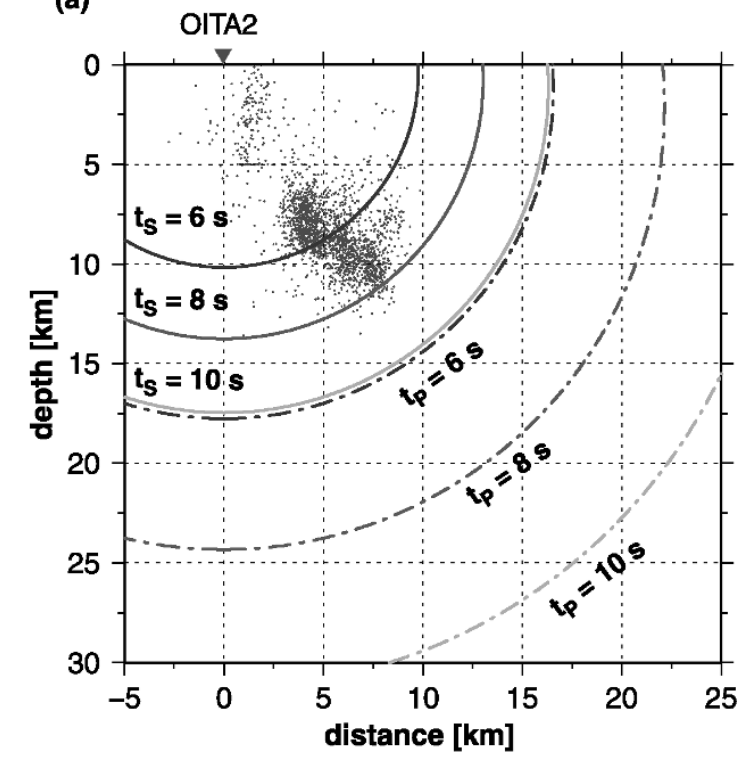

(b) OITA2

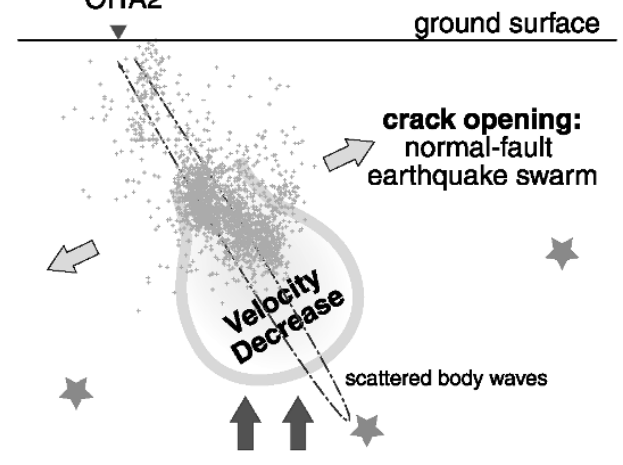

Fluid Injection?

\section{scatterers}

Fig. 5. (a) Cross section showing hypocenters of earthquakes along line A-B in Fig. 1 with isochronal curves for backscattered $P$-waves (dash-dotted line) and $S$-waves (solid line) from the OITA2 station at lag times of 6,8 , and $10 \mathrm{~s}$. (b) A schematic illustration of the proposed model of the velocity change mechanism.

\section{Discussion}

\subsection{A cause of the temporal change}

Such change in ACF can be explained not only by seismic velocity change but also by rainfalls (Sens-Schönfelder and Wegler, 2006) or contamination by earthquake signal. During the period when the earthquake swarm was very active (June, 2007 and October 30, 2007), the continuous record at the OITA2 mainly consisted of an earthquake signal; this is no longer a noise, which may violate the assumption of the seismic interferometry. However, the change in ACF lasted about 4 months, which is longer than the characteristic period of the earthquake swarm. We also manually con rmed that very few earthquake signals appeared in the continuous record at the frequency band of $1-3 \mathrm{~Hz}$ after 1 month from the rst activity, and after 2 days from the second activity, respectively. Although the rainy season in this area stretches from June to July, there is no such seasonal effect in October that could cause such changes. In addition, we con rmed that no seasonal changes in ACFs occurred in other years of 2006 and 2008 at the same station. Therefore, this observation is most plausibly explained by seismic velocity decrease and recovery. The ACF of ambient noise can be interpreted as a sum of waves backscattered by random heterogeneity in the lithosphere with the wave source and receiver at the same location (Sens-Schönfelder and Wegler, 2006) based on the single scattered theory (Aki and Chouet, 1975).

\subsection{Localized velocity change}

The fact that the ACF phase delay was detected only at OITA2 in a limited time range suggests that the velocity change is localized near the OITA2 station. The temporal change should not be attributed to the incidence of strong motion because the earthquakes were too small to cause nonlinear effects in shallow sediments. If the velocity change occurred very close to the station, the expected ACF delay would have shorter lag times than those actually observed. From these observations, we propose that the observed ACF packet consists mainly of backscattered body or Rayleigh waves that pass through the hypocenter or epicenter area.

We observe signi cant phase delay of ACF continued for 1 month for the rst earthquake swarm. The maximum observed ACF delay is $0.15 \mathrm{~s}$ at a lag time of $10 \mathrm{~s}$ (Fig. 3), resulting in a $1.5 \%$ velocity decrease. This determination assumes that the seismic velocity decreased homogeneously in a vast area that includes the seismic station and takes into account that ACF phase delay increases proportionally to lag time (Sens-Schönfelder and Wegler, 2006; Brenguier et al., 2008a). However, it is noteworthy that the lag-dependent ACF phase delay for both active periods is localized at similar lag times of about 6-12 s, even though the two periods had different hypocenter locations. This also suggests that the location of the changes are localized in a common area.

\subsection{Interpretations}

Since both body and Rayleigh waves may contribute to the Green function in this frequency range, there is no direct evidence to distinguish that which is dominant in the observed ACF. If we assume the backscattered Rayleigh waves to be a cause of the temporal change, a possible location of the velocity change should be at around the ground surface. Isochrones for Rayleigh waves at lag times of 6 , 8 , and $10 \mathrm{~s}$ are located at a horizontal distance of 6,8 , and $10 \mathrm{~km}$ from the station, respectively, assuming $2 \mathrm{~km} / \mathrm{s}$ as a group velocity of the Rayleigh waves. Due to the sensitivity of Rayleigh waves in depth, the maximum depth of velocity change is limited to about $1 \mathrm{~km}$ in this frequency range. If the constituents of the ACF are Rayleigh waves, the non-linear effect in the sediment layer at just above of the hypocenter could be one reason for the velocity change. However, the location of velocity change is $6-10 \mathrm{~km}$ from the station; this may be too far from the epicenter, especially 
for the second activity that occurred at beneath the OITA2 station.

Assuming that the constituents of the ACF are backscattered body waves, we calculated the isochronal curves of the two-way travel time of backscattered waves from the station. A 1-D velocity structure (Matsubara et al., 2008, gure 2) is used for the ray tracing. We note that the same velocity structure is used for the hypocenter location, so that the relative location between earthquakes and isochronal curves is reliable. Figure 5(a) shows the cross section of the isochronal curves of $P$ and $S$ waves which correspond to lag times of 6,8 , and $10 \mathrm{~s}$ along the pro le A-B in Fig. 1(a). The isochrones of scattered $S$ waves samples around the hypocenter, while $P$ waves samples deeper extent of swarm. In the case of $P$ waves, the possible scattering structure must be located farther from the station than the earthquake swarms hypocenters even for the shortest lag times where a temporal change appears $(6 \mathrm{~s})$.

It is noteworthy that isochrones of the $P$-wave for the lag time of $6 \mathrm{~s}$ and those of the $S$-wave of $10 \mathrm{~s}$ sample almost same depth of just beneath of the hypocenter area. At these two lag times, we observe small and large temporal changes at these time windows. One possible interpretation is that the temporal changes occur at the common small area beneath the epicenter area at depths of $\sim 15 \mathrm{~km}$, and the change is observed by backscattered $P$-waves and $S$-waves (Fig. 5(b)). Since this area is a part of the Hohi volcanic area (Kamata, 1989), which has an extensional stress eld, it is possible that the velocity change is caused by the inclusion of uid from deep within the hypocenter area. An intermittent uid supply may cause the earthquake swarm in association with the sudden velocity decrease. Fluid injection up into shallower regions triggered the two earthquake swarms, dominated by normal-fault type earthquakes. The north/south-oriented extensional stress eld may promote crack opening, resulting in the uid injection. Comparison of seismic activity and the magnitude of the ACF phase delay suggests that the volume of the rst uid injection was much larger than that of the second. Recovery of seismic velocity may be caused by diffusion of the uid within the crust. That this injection occurred deep within the crust may explain why no geodetic change was associated with the swarms.

\section{Concluding Remarks}

Using the PII technique, we found reproducible temporal changes in seismic velocity in association with seismic swarm in NE Kyushu, Japan. By monitoring daily changes in noise ACF, a systematic phase delay lasting about 4 months was observed for two major periods of earthquake activities. From the lag-time dependence of ACF, a localized seismic velocity decrease which relates to the swarm activity is proposed as a possible model that may explain the observation.

The PII technique enables researchers to monitor the crustal structure at a temporal resolution of 1 day with small computational effort, which is quite suitable for real time processing. Even with changes in the crustal structure that are not geodetically detectable as in this study case, the noise correlation may contain information on the dynamic process of crustal structure through seismic velocity change. Standing, long-range monitoring that provides dense array data is becoming more available. The use of recently installed systems such as the Hi-net (Okada et al., 2004) and USArray (Meltzer et al., 1999), can support wider application of this new tool for the monitoring of crustal structure.

Acknowledgments. The authors would like to thank Tatsuhiko Hara, Ulrich Wegler, and an anonymous reviewer for their valuable comments. We used continuous seismic traces recorded by the Japan Meteorological Agency at the OITA2 station. A part of this research was carried out as a part of the "Research Project for Crustal Activity based on Seismic Data" conducted by the National Research Institute for Earth Science and Disaster Prevention.

\section{References}

Aki, K. and B. Chouet, Origin of coda waves: Source, attenuation and scattering effects, J. Geophys. Res., 80, 3322-3342, doi:10. 1029/JB080i023p03322, 1975.

Brenguier, F., M. Campillo, C. Hadziioannou, N. M. Shapiro, R. M. Nadeau, and E. Larose, Postseismic relaxation along the San Andreas Fault at Park eld from continuous seismological observations, Science, 321, 1478-1481, doi:10.1126/science.1160943, 2008a.

Brenguier, F., N. M. Shapiro, M. Campillo, V. Ferrazzini, Z. Duputel, O. Coutant, and A. Nercessian, Towards forecasting volcanic eruptions using seismic noise, Nature Geosci., 1, 126-130, doi:10.1038/ngeo104, 2008b.

Campillo, M. and A. Paul, Long-range correlations in the diffuse seismic coda, Science, 299, 547-549, doi:10.1126/science.1078551, 2003.

Kamata, H., Volcanic and structural history of the Hohi volcanic zone, central Kyushu, Japan, Bull. Volcanol., 51, 315-332, doi:10. 1007/BF01056894, 1989.

Matsubara, M., K. Obara, and K. Kasahara, Three-dimensional P-and Swave velocity structures beneath the Japan Islands obtained by highdensity seismic stations by seismic tomography, Tectonophysics, $\mathbf{4 5 4}$, 86-103, doi:10.1016/j.tecto.2008.04.016, 2008.

Meltzer, A., R. Rudnick, P. Zeitler, A. Levander, G. Humphreys, K. Karlstrom, G. Ekström, R. Carlson, T. Dixon, M. Gurnis, P. Shearer, and R. van der Hilst, USArray initiative, GSA Today, 9(11), 8-10, 1999.

National Research Institute for Earth Science and Disaster Prevention, Seismic activity at the middle Ohita Prefecture, June, 2007, Rep. CCEP, 79, 605-607, 2008.

Nishimura, T., S. Tanaka, T. Yamawaki, H. Yamamoto, T. Sano, M. Sato, H. Nakahara, N. Uchida, S. Hori, and H. Sato, Temporal changes in seismic velocity of the crust around Iwate volcano, Japan, as inferred from analyses of repeated active seismic experiment data from 1998 to 2003, Earth Planets Space, 57, 491-505, 2005.

Ohmi, S., K. Hirahara, H. Wada, and K. Ito, Temporal variations of crustal structure in the source region of the 2007 Noto Hanto Earthquake, central Japan, with passive image interferometry, Earth Planets Space, 60, 1069-1074, 2008

Okada, Y., K. Kasahara, S. Hori, K. Obara, S. Sekiguchi, H. Fujiwara, and A. Yamamoto, Recent progress of seismic observation networks in Japan-Hi-net, F-net, K-NET and KiK-net, Earth Planets Space, 56, xv-xxviii, 2004.

Poupinet, G., W. L. Ellsworth, and J. Frechet, Monitoring velocity variations in the crust using earthquake doublets: An application to the Calaveras fault, California, J. Geophys. Res., 89, 5719-5731, 1984.

Sawazaki, K., H. Sato, H. Nakahara, and T. Nishimura, Temporal change in site response caused by earthquake strong motion as revealed from coda spectral ratio measurement, Geophys. Res. Lett., 33, L21303, doi:10.1029/2006GL027938, 2006.

Sens-Schönfelder, C. and U. Wegler, Passive image interferometry and seasonal variations of seismic velocities at Merapi Volcano, Indonesia, Geophys. Res. Lett., 33, L21302, doi:10.1029/2006GL027797, 2006.

Shapiro, N. M., M. Campillo, L. Stehly, and M. H. Ritzwoller, Highresolution surface-wave tomography from ambient seismic noise, Science, 307, 1615-1618, doi: 10.1126/science.1108339, 2005.

Snieder, R., A. Grêt, H. Douma, and J. Scales, Coda wave interferometry for estimating nonlinear behavior in seismic velocity, Science, 295, 2253-2255, doi:10.1126/science.1070015, 2002. 
Vidale, J. E. and Y. G. Li, Damage to the shallow Landers fault from the nearby Hector Mine earthquake, Nature, 421, 524-526, doi:10. 1038/nature01354, 2003.

Wegler, U. and C. Sens-Schönfelder, Fault zone monitoring with passive image interferometry, Geophys. J. Int., 168, 1029-1033, doi:10. 1111/j.1365-246X.2006.03284.x, 2007.

Wegler, U., H. Nakahara, C. Sens-Schönfelder, M. Korn, and K. Shiomi, Sudden drop of seismic velocity after the $2004 M_{w} 6.6$ mid-Niigata earthquake, Japan, observed with Passive Image Interferometry, J. Geo- phys. Res., 114, B06305, doi:10.1029/2008JB005869, 2009.

Yamawaki, T., T. Nishimura, and H. Hamaguchi, Temporal change of seismic structure around Iwate volcano inferred from waveform correlation analysis of similar earthquakes, Geophys. Res. Lett., 31, L24616, doi: 10.1029/2004GL021103, 2004.

T. Maeda (e-mail: maeda@eri.u-tokyo.ac.jp), K. Obara, and Y. Yukutake 